\title{
16. SINFONIA AVANTI IL BARCHEGGIO BY ALESSANDRO STRADELLA IN INTERPRETATIONS OF THE TRUMPETERS IULIAN HOREZ AND MIROSLAV KEJMAR
}

Iulian Horez ${ }^{145}$

\begin{abstract}
Alessandro Stradella is a lesser-known composer in trumpet works. However, the Sinfonia avanti il Barcheggio is of great beauty and is written perfectly trumpet. The original is composed for trumpet in $C$, but the key of D major in which the concerto played with trumpet in $C$ is written poses the biggest tuning problems. For this reason, I recommend for this concert a trumpet in A. The tuning will be much better, it will be played in F major, the natural notes of the trumpet will be used a lot $(C, E, G)$.
\end{abstract}

Key words: trumpet interpretive technique, trumpet tuning

\section{Introduction}

After 30 years of playing in a symphony orchestra (the Moldova Philharmonic, Iasi), under the "dictatorship" of the baguette, it is completely different when you play solo in front of an orchestra. Even if in those 30 years of activity there were works in which the trumpet had to interpret very difficult solo parts (symphonies by Gustav Mahler, Dmitri Shostakovich, Richard Wagner, Richard Strauss, Mesiah by G. Fr. Handel, etc.), there is no comparison with the feeling and responsibility you have when you are a soloist in front of the audience. The bandmaster is no longer a "God", as you feel when you sing in the orchestra. As a soloist you feel more important, having a greater responsibility than the bandmaster, you feel that you must listen yourself, you must read the interpretive message of the works you have to play. I had the opportunity to be a soloist in 2002 and 2006. I performed in the biggest concert halls in Germany and the Netherlands as a soloist for the work Sinfonia avanti il Barcheggio for the trumpet and orchestra, accompanied by the Orchestra of the Moldova Philharmonic from Iasi, with G. B. Rohmanick as bandmaster.

Miroslav Kejmar is the first trumpet in the Prague Philharmonic Orchestra, Czech Republic. Miroslav Kejmar, in his performance, also used a trumpet in $A$, a Schilke brand - Germany. They are the best, but also the most expensive.

\section{Discussions}

I played this concert with a Yamaha Xeno trumpet, which leaves a little to be desired in tunning and in the opening of the sound. Thus, I had these tunning problems when I sang as a soloist Sinfonia avanti il Barcheggio by Stradella. The note $D$ in the upper octave (against $A$ central) in the acute register of the trumpet was a little lower in tunning, which forced me to use "false" supporting positions. The Allegro tempo (the quarter $=96$ ) made this noticeable to the public, however, and a professional trumpet would have noticed that I use a phrasing different from the normal one. Coming back to the concert, the work is written in the acute

\footnotetext{
${ }^{145}$ Associate Professor PhD. habil., "George Enescu” National University of Arts from Iaşi, Romania, email:
} horez.iulian@yahoo.com 
register of the trumpet (from $F^{2}$ to $G^{3}$. All four parts require special support and effort from the instrumental soloist. When playing in the acute register of the trumpet, the air pressure is very high, the air volume is consumed very quickly, and the composer has taken this into account, the musical phrases not being longer than 3-4 measures.

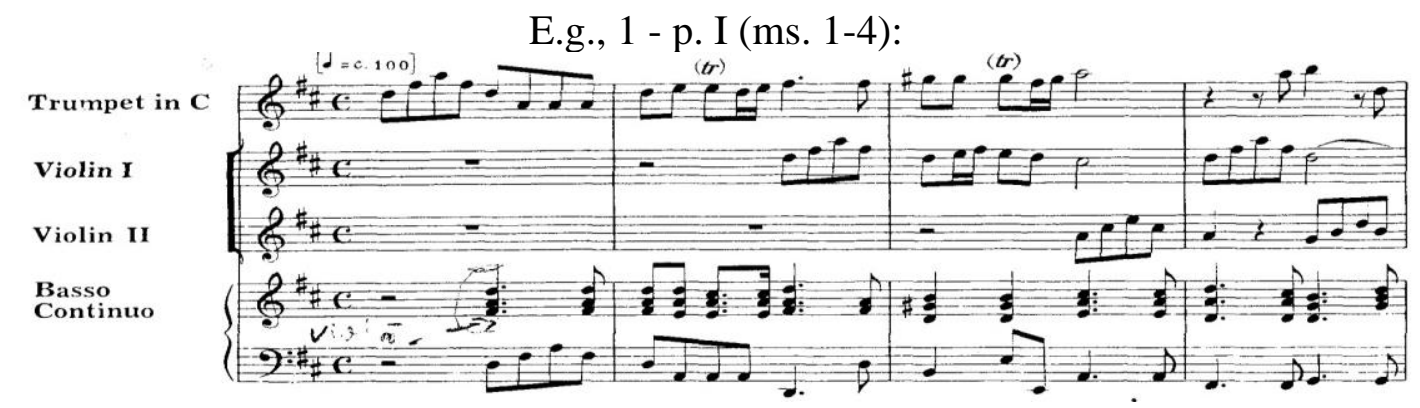

I played this concert beginning with a soft attack and with a sound of mezzo forte toward forte. Unfortunately, the composer shows no tone at the beginning of the concert. This is also the reason that prompted Miroslav Kejmar to start the concert in a full forte tone with a little warrior air.

It is worth mentioning that Miroslav Kejmar, the best Baroque music performer from the Czech Republic, has a very clear, fine attack and an open sound. The Czech school has always been superior to the Romanian one in brass instruments, with a great tradition and one of the best schools in Europe, after the German and French school.

Arban (1850-1920), a great teacher and trumpet, a descendant of this tradition school, wrote a trumpet method that has then become well known, the method that is used in all schools in Europe, even today. Coming back to the concert, very important in the singing is that when going up from the acute register to the super-acute one, the notes should not narrow as a sound, which happens to very many trumpeters. It is a generally valid law, not just for Baroque music. This is due to the decrease in the air column outlet opening now the tone goes up. The solution is to increase the air pressure as the non-sizing of facial muscles also grows.

At Miroslav Kejmar, you can see the equality of sounds in intensity, regardless of the trumpet register. I did the same, but as an explanation, if in the average register of the trumpet the difference in air pressure is very small, in the acute register, this air pressure is much higher from one note to the next, in the ascending direction.

E.g., 2 - p. I (ms. 20-22):

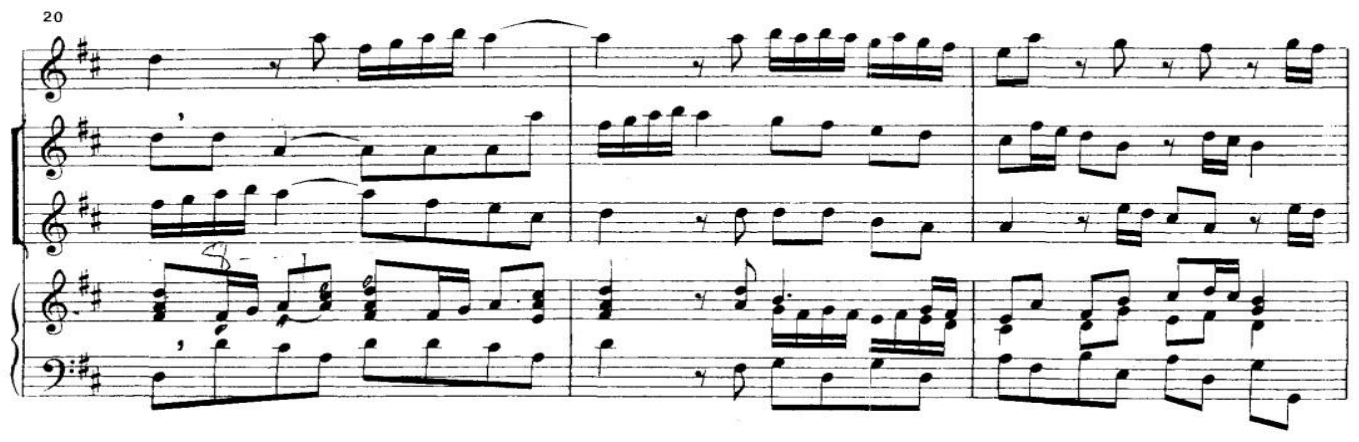

As a conclusion for the first part, if I observed, in general a tint of too much sonority at Miroslav Kejmar I preferred a soft, cameral sound, also taking into 
account the orchestra that is very "thin".

I have always been convinced that it is much more difficult to play in the acute register in high notes values (quarters, half) than in low values (eights, sixteenths). Supporting high values notes in acute requires much greater physical effort, causes much greater and faster facial muscle fatigue. The reason for this is that these high values force the facial muscles to high vibrations over relatively long periods of time. But this prevents the circulation of the blood in muscles, which immediately gives a sense of fatigue. When playing in low values in the acute register, there is also the mental feeling that time is passing faster, which is misleading, the explanation being that in the situation of low values and notes at different heights, breaks of fractions of seconds occur, time in which the muscles have time to re-oxygenate by increasing or decreasing the diameter of the air column outlet hole.

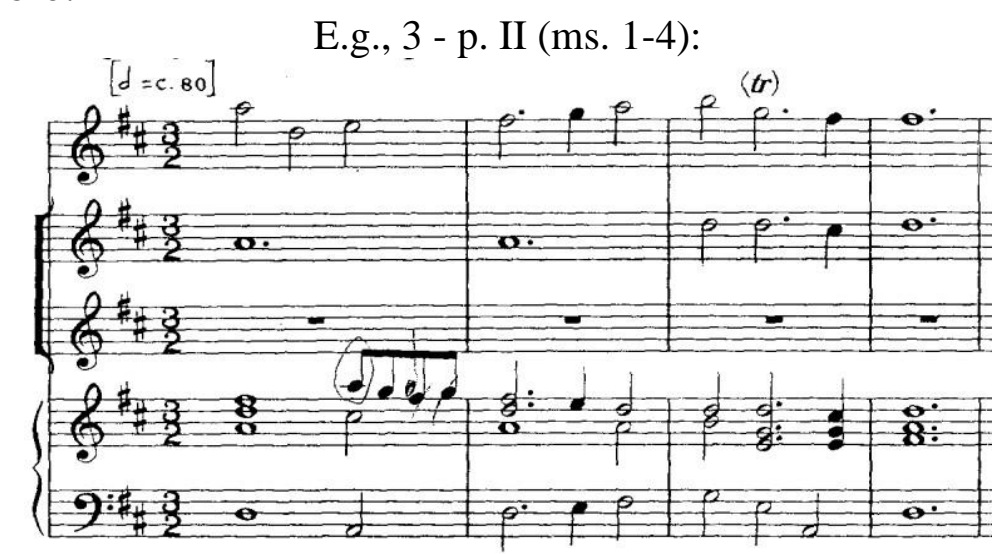

In the amplitude of the sound, I also approached Miroslav Kejmar, in the second part, a calm, cameral mezzo forte dolce. Passages appear where it is impossible to breathe due to writing and only one volume of air must be used. I have also observed a whole breathe for the whole phrase at Miroslav Kejmar, but in the last two measures it is felt that he is losing support due to the exhaustion of the air volume.

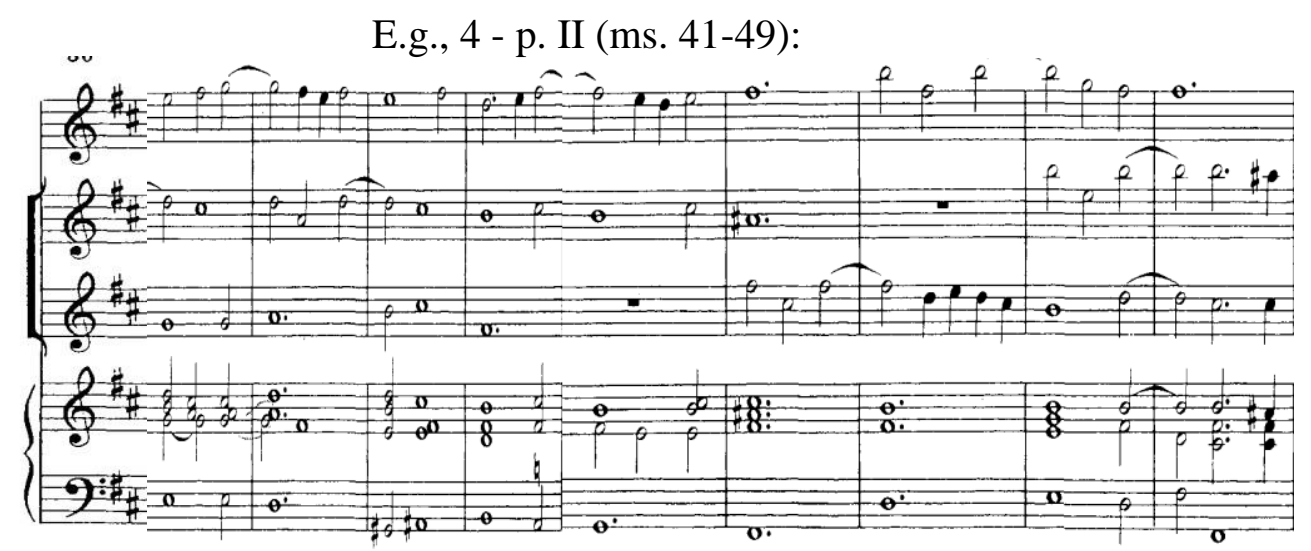

Always the medial parts of a concert or sonata, in slow movements (Andante, Adagio, Grave) are the most tiring to a brass blowing instrument because they require a higher physical effort.

The third part is a move where you can show your technical possibilities, your virtuosity. Miroslav Kejmar approaches a slightly more stable tempo against my interpretation. I do not agree with this, as it loses out of the shine, of the message for impressing the audience, through the technical virtuosity that can be demonstrated in this part of the concert. I think it is more impressive for the public 
to have a message of technical virtuosity than a message of static grandeur. If Niccolò Paganini had written his Whims in Andante, they would have lost their fame nowadays. The speed of the tempo (quarter $=112$ ) forced me to use the simple staccato at the upper limit. Miroslav Kejmar also uses the simple staccato, making it easier for him to do so, given the tempo a little more stable. The double the staccato should not be used in any circumstance, which would generate the loss of clarity and brightness in the notes.

\section{E.g., 5 - p. III (ms. 1-4):}

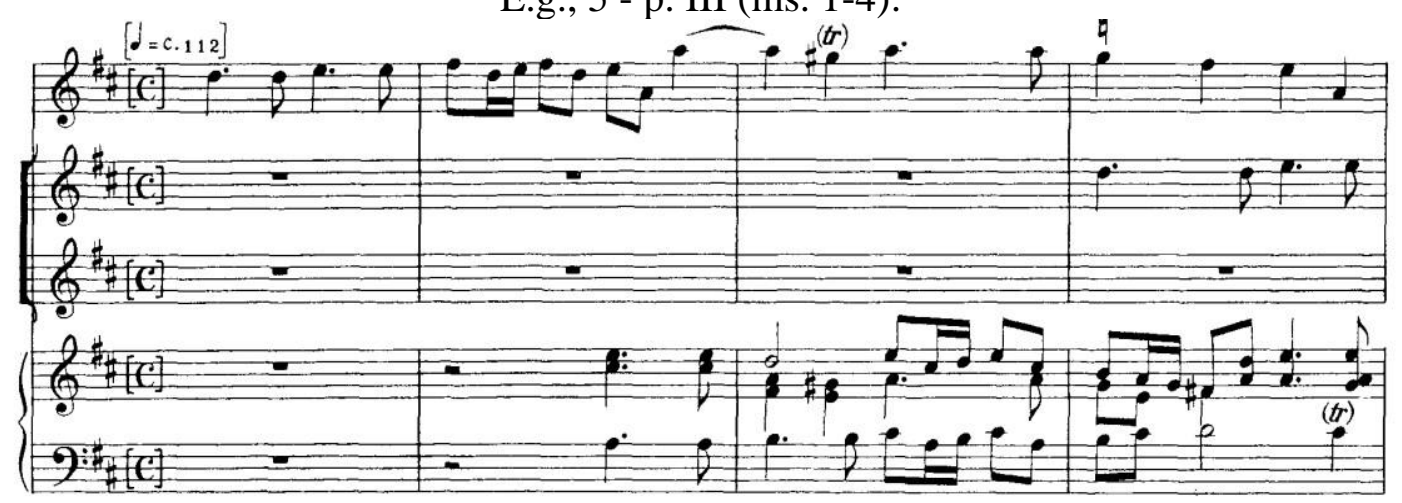

Miroslav Kejmar has a very good support of notes in the acute, which demonstrates a very good diaphragm breath. If we also add the trile of two measures between $C$ and $D$, which is very difficult between these two notes, I can say that it successfully resolves this passage. Personally, I felt this was one of the most difficult moments in this concert.

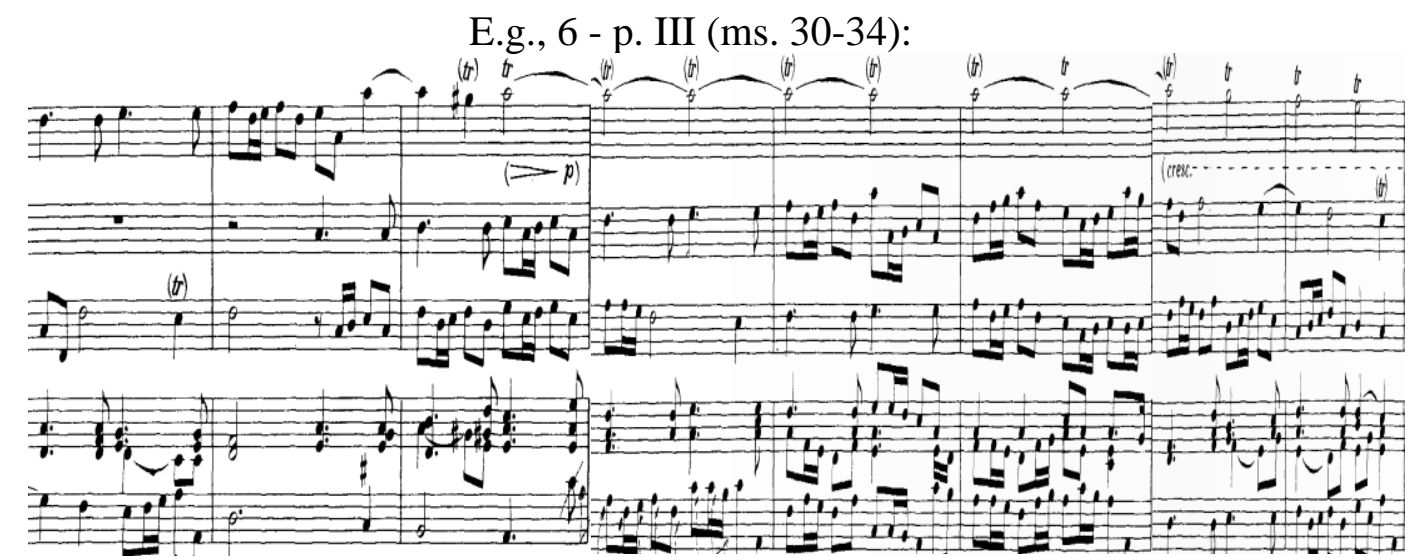

I noticed in Miroslav Kejmar a little pressed attack during the entire concert, but I think it is also about his personality or the general way of singing. Personally, I prefer a soft but clear attack, the sound starting from a very small tone without hearing the attack of the tongue. The sound equality, despite the large interval jumps (the quarter, the quart) especially in the acute register shall be admired at Miroslav Kejmar. The professionalism of a trumpeter consists of the following qualities:

- not to change the tempo given, an essential condition upon which all others depend. The tempo may be rare compared to the one imposed, but human, given that the motivation is poor professional training, especially in the instrumental technique. But to increase the tempo compared to the one given at the beginning, is totally inaccessible.

- to have a warm, pleasant sound in all the trumpet registers, and not a harsh, strident, or hard one. This is particularly necessary regarding the trumpet, which is an instrument with a penetrating sound, and a very large number of trumpeters fall 
into a hard, harsh, military sonority.

- lightness and smoothness in attack. The attack must be imperceptible, the notes must be heard as if it were not a language attack, which is the case regardless of the trumpet register.

- lightness in the singing, regardless of the rhythmic formulas or intervals between notes.

- the very good mastery of the single, double, and triple staccato.

- very good diaphragm breathing (not thoracic), with a good air volume control during the sentences.

- and finally, a correct position when blowing. Non-stretching, non-straddling the lips, leads to the strangulation of the air column toward the acute register. The facial muscles must be as relaxed as possible to have a soft, pleasant tone. Tension leads to a harsh, metallic sound, a lot of lightness is lost and cannot be played in the acute register.

These are the basic conditions for a trumpeter to become a good professional, and to all this, a high volume of work and study is added. Coming back to our concert, the fourth part, Allegro (quarter $=96$ ), offers huge possibilities to display lightness and precision in the acute register of the trumpet. Here, too, for Miroslav Kejmar, I preferred a tempo a little faster, but without losing sight of the clarity of the notes. In this last part, Miroslav Kejmar must be admired for the constant in the tempo, the brightness of the sound and the clarity of the notes. The same breathing problem, as in the second part, occurs at the beginning of this part, where the volume of air must be measured from a single breath, so that it reaches for all 12 measures of the sentence.

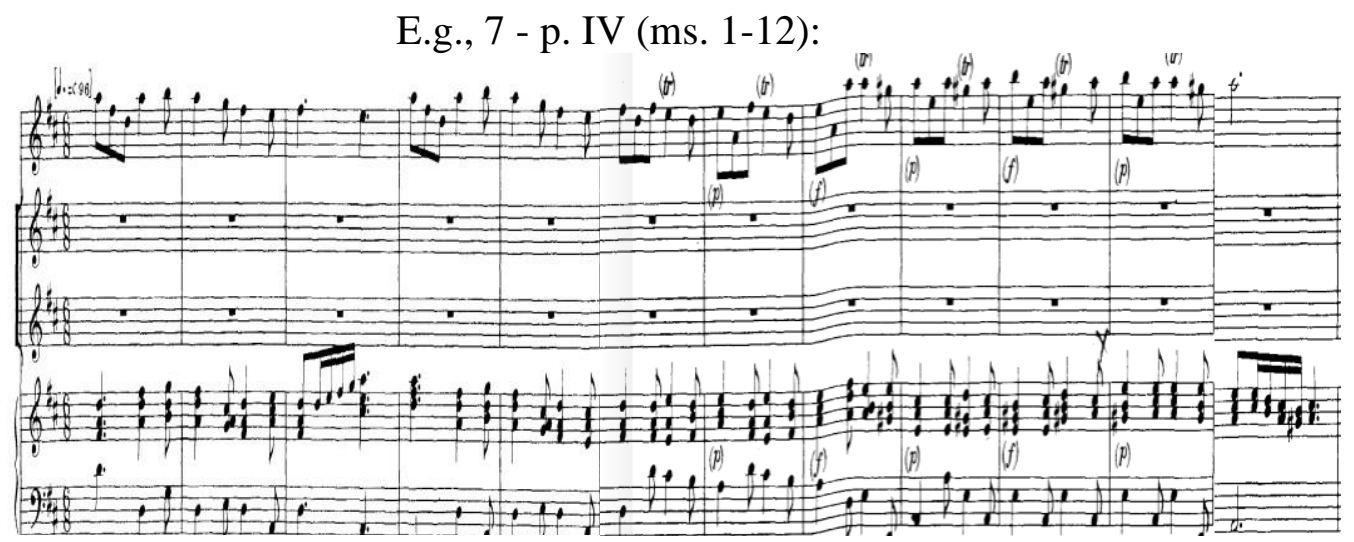

As a special feature, if Miroslav Kejmar has repeated the last measure of the concert as written by the author, I personally allowed myself to sing the last note at an interval of ascending sexta against the real sound ( $F$ to the trumpet in $A, \mathrm{D}^{2}$ to piano), feeling that an extra shine is obtained for the end of the concert.

\section{Conclusions}

In conclusion, I consider Miroslav Kejmar one of the most important baroque music trumpeters, a Czech school peak, endowed with special qualities for this kind of music. Personally, I do not think that there are any major differences between my interpretation and that of Miroslav Kejmar, convinced that I have managed to play this concert on a professional level, proving once again that Baroque music can be played by Romanians in Europe's biggest concert halls. There are many Romanian trumpeters, such as Iancu Vaduva - professor of the 
Academy of Arts in Bucharest, Ion Dornescu - first trumpet in the Bucharest Radio Symphonic Orchestra, Carstea Sergiu - first trumpeter in the Opera orchestra in Timisoara) who made the name of our country known.

\section{References}

1. Blume Friedrich - Barock, in Musik in Geschichte und Gegenwart, în: Barenreiter - Verlag Kassel und Basel, 1949-1951

2. Fredy, Ladislau - Telemann, Bucureşti, Editura Muzicală, 1971

3. Herman, Vasile - Originile şi dezvoltarea formelor muzicale, Bucureşti, Editura Muzicală, 1982

4. Iliuţ, Vasile- $O$ carte a stilurilor muzicale, vol. I, București, Editura Academiei de Muzică, 1996

5. Pascu, George, Boţocan, Melania - Carte de istorie a muzicii, vol. I, Iaşi, Editura Vasiliana Boţocan, Melania 98', 2003

6. Ştefănescu, Ioana $O$ istorie a muzicii universale, vol. I, Bucureşti, Editura Fundaţiei Culturale Române, 1995

7. xxx -Grove's Dictionary of Music and Musiciens, Londra, Macmillan \& Co LTD, 2002

8. xxx -Encyclopedie de la Pleiade, Histoire de la Musique, Paris, 1960

9. xxx -Enciclopedia della musica, Milano, Ricordi, 1964

10. xxx-Encyclopedie de la Musique, Paris, Fasquelle, 1961 